\title{
A Study on How to Instruct Students in Field Work Performance \\ -Instructing Students Who Had Problems in Learning the Physical Therapy Practical Process-
}

\author{
KAZUHiko SHIMIZU, MA, RPT \\ Kitasato University, School of Allied Health Sciences, Faculty of Rehabilitation, \\ 1-15-1 Kitasato Sagamihara, Kanagawa 228, Japan
}

\begin{abstract}
The author has compiled a list of 76 items to be learned by students in the Field Work Performance (FWP) program with the notion of framing a general idea of the Physical Therapy Practical Process (PTPP), and used these items to prepare a Self-Evaluation Achievement Checklist (SEAChecklist) in the form of a questionnaire. Based on the SEA-Checklist, research has been carried out on the performance levels of students who have been engaged in clinical training. This study was carried out on students with mistakes in the FWP. Three types of instruction methods were carried out: the individual objective setting and executing type (A); the individual objective proposed type (B); and the experienced objective setting type $(\mathrm{C})$. The study was performed by using these three methods and an examination of determined effects was made to learn if any difference can be found in learning PTPP. The chi-square test was carried out from the number of passing items and nonpassing items of each type. No significant difference was observed between any group at the beginning of the training. It was also found that the marks and the passing rates for all groups increased significantly after the training. A significant difference ( $\mathrm{p}<0.05$ ) was observed between types $\mathrm{A}$ and $\mathrm{C}$, but not between types $\mathrm{A}$ and $\mathrm{B}$, and types B and C. To review penetration of the effect of learning, when the level of rating criteria was raised one rank, to "almost satisfactory" from "achieved in some way" in the 7-stage rating, significant differences between types $\mathrm{A}$ and $\mathrm{B}(\mathrm{p}<0.01)$ on the one hand, and those between types $\mathrm{A}$ and $\mathrm{C}$ on the other were confirmed. In determination of the effects of the three types of instruction for those with wrong steps in the FWP, it was noted that type A was the most effective method, type C was less effective, and type B was intermediate. It was possible to identify students with wrong steps in the FWP by using the SEA-Checklist obtained in the first study and to grasp the contents of the wrong steps. Working out the plans for overall targets and individual student targets was made easier. In FWP instruction, it was effective not only to post an overall target, but also to adopt the instructing method to correct each case as it may require by evaluating the situation as the students were actually engaged in FWP. In a sense, the use of instruction of individual target setting and excuting type (type A) turned out to be effective. Although the current situation does not allow use of this method, it was suggested that the execution of a instruction method of at least an individual target proposed type (type B) was required. This method was considered effective for the students with no mistakes in FWP.
\end{abstract}

Key words: Education, Field Work Performance, Physical Therapy Practical Process, Self-Evaluation Achivement Checklist. 


\section{INTRODUCTION}

Field Work Performance programs (referred to below as "FWP") are recognized as the most important programs in the Physical Therapy Practical Process (PTPP) education; however, the situation faces many problems. No previous field-work studies on FWP for the PTPP has been carried out.

The author has extracted 76 learning items in the FWP with the notion of framing a general idea of PTPP, and used these items as a Self-Evaluation Achievement Checklist (hereafter referred to as "SEA-Checklist") in the form of a questionnaire. A study of the SEA-Checklist made it possible to grasp the performance levels of the students and to obtain the required knowledge and information. (1st study as retrospective study by the author in 1992).

The SEA-Checklist contains the following information ${ }^{1)}$ 2).

* The overall objectives of the instruction programs worked out each Field Work Level became easier to be set up.

* The progress of the FWP differs in each of the 76 items, which may be difficult to learn, depending on when the FWP is carried out.

* The group with poor performance has much difficulty in items to be learned, compared with the good performance group.

* Longitudinal research showed that the learning curves of the students were classified into six types. It also revealed that the individual objective of each student must be shown and that instruction is necessary according to the individual's performance level in each FWP.

* The individual objective of each student becomes easy to be devised.

* Students who made especially big mistakes (the number of low performance students in the FWP who obtained low scores from the SEAChecklist) increases in number as the FWP progressed, accounting for $13.0 \%$ of students in the final field work levels. Therefore, it turns out that the appropriate instruction should be provided an earlier stage for these mistakes.

In consideration of the above information, this study focused on the students with mistakes in the PTPP with the aim of improving instruction in the FWP. Several methods had been previously tried in examining the instruction methods, and its effect was judged afterward. This was thought to provide important knowledge and information on reviewing the instruction methods for students who had no wrong steps in the FWP.

For those made mistakes in the FWP, three types of instruction methods were carried out: the individual objective setting and executing type (A); the individual objective proposed type (B); and the experienced objective setting type (C).

The primary objective of this study was to examine the effects of instruction to see if any differences could be found in the ways of performing the PTPP.

\section{METHOD}

\section{Determination of term and sample of this study}

This study was carried out during FWP between September and December 1993 (the first and second terms of the third grade) in the form of prospective study. The FWP in each term is provided on the basis of 8 weeks as a unit.

Two schools, $\mathrm{H}$ and $\mathrm{T}$, agreed to cooperate in this study, and the author requested the $16 \mathrm{H}$ students (the author was a member of this school's faculty) and the $20 \mathrm{~T}$ students to fill in checklists when the first term of the third grade was finished, from which a Self-Evaluation Achievement Rate (SEAR) was caltulated.

The integrated performance records were transferred from the students' clinical performance records. A rating was given to each item in the performance records, and the marks obtained for all recorded items were composited.

As in the first study (1992), the average values and the standard deviations of the marks for all items in the performance record and in the SEAR were obtained.

In reference to the marks, the students with a value of less than the average standard deviation of $-1 / 2$ were regarded as those with mistakes in the FWP for the PTPP.

Two students of type A and three of type B from $\mathrm{H}$ school and five of type $\mathrm{C}$ from $\mathrm{T}$ school were chosen as subjects of this study.

\section{Outline of each instruction method}

For type A students, the FWP object and individual scaled performance objective items were planned by the faculty teaching staff at school $\mathrm{H}$ 
and presented to the Supervisors (SV). Thereafter the faculty teaching staff and SVs shared the performance levels of the students by using the SEA-Checklist when they need to know; they then designed and corrected the instruction plans after deliberation.

For type B students, the FWP object and individual scaled performance objective items were prepared by the faculty teaching staff based on the results of the SEA-Checklist. They were presented only to the SVs, but no adjustment of the plan was made thereafter.

For type C students, only conventional instruction was provided by the SVs based on their experience. And the results of the SEA-Checklist were not shown to SVs.

\section{Determining the effects of instruction}

In the SEA-Checklist, the 7-stage rating criteria from "could do well" to "could not do completely" were applied to each item in the form of a questionnaire asking the students their achievement ratings in performance objective items. When those data were processed statistically, the 7-stage rating criteria were converted into a 2 -stage criteria, "achieved" and "not achieved". "Achieved" was for students with a rating better than "achieved in some way", and "not achieved" for students with a rating worse than "achieved in some way".

After converting the number of "Achieved" items, the "Achieved score" was obtained as a percentage of the number of the items "Achieved" out of the 76 items in the SEA-Checklist.

To check the degree of learning level, new criteria were made to test the the level of "almost achieved", and statistical tests were also carried out.

To determine the difference among the three groups, the passing and not passing numbers of each of the 76 items were totaled, and chi-square tests were carried out between each group. The revised value by Fisher's method was adopted as a significant probability.

The inclination of the rating before and after the FWP was examined from the performance records rated by the SVs before and after the FWP by using 4-stage rating from "excellent" to "unsatisfactory."

\section{RESULTS}

Comparison with integrated performance records in clinical training

In type $A$, improvement in the performance record was found in one student. The 4-stage rating changed from "unsatisfactory" to "excellent". However, there was no improvement in the other students.

In type B, one student was found to improve. The rating changed from "unsatisfactory" to "excellent". No improvement was observed in the other two students.

In type $\mathrm{C}$, improvement was observed for two students, and their changes were from "unsatisfactory" to "good". No change was seen in the three students.

In type $\mathrm{C}$, deterioration in the integrated performance record was observed in two students, but not in students of types A and B.

\section{Comparison of marks obtained for Self-Evaluation Achievement rating}

Table 1 shows the marks obtained for SEAR before and after the training. When differences in subjects were observed, the minimum value was zero and the maximum value was 45 ; the average was 28.1. No difference in value before and after the clinical training was observed in only one subject, but the values obtained for others increased. When the average for each type of instruction and the difference obtained before and after the training was obtained, it was found that type A subjects averaged 32.0, type B 31.7, and type C as low as 24.6. From the viewpoint of increasing rate, type $\mathrm{C}$ was lower than the other two (1.5).

\section{Determination of the effect of Self-Evaluation Achievement rating marks (passing rate) by test}

When the passing rate for each type was obtained for the test performed from the number of passing and nonpassing items, it was found that the passing rate at the beginning of the practice was $48.0 \%$ for type A, $41.7 \%$ for type B, and $46.4 \%$ for type $\mathrm{C}$; no statistically significant difference was observed. It was also found that the marks obtained and the passing rate for all groups increased significantly $(\mathrm{p}<0.01)$ before and after the training. A significant difference $(\mathrm{p}<0.05)$ was observed between types $\mathrm{A}$ and $\mathrm{B}$ after the training, but no 
significant differences were observed between types A and B, and between types B and C.

To review penetration of the effect of learning, when the level of rating criteria was raised one rank, to "almost satisfactory" from "achieved in some way" in the 7-stage rating, a significant difference $(p<0.01)$ was confirmed between types A and $\mathrm{B}$, and between types $\mathrm{A}$ and $\mathrm{C}$. A significant inclination was observed between types B and C.

In determination of the effect of three types of instruction for those with mistakes in the FWP, it was noted that type A was the most effective method, type $\mathrm{C}$ was the least effective, and type $\mathrm{B}$ was intermediate.

\section{DISCUSSION}

According to the tests on the passing rate for SEAR of each group before the training, no significant difference in the groups was observed, but it seemed no deviations in sampling, as no large difference in the integrated rating was observed even in a small number of samples.

According to a comparisons of overall marks, no students had satisfactory marks for types A and $\mathrm{B}$, and two students of type $\mathrm{C}$ had unsatisfactory marks. The study was not intended to review instruction methods for improving the marks of the

Table 1. Comparison of marks obtained in self-evaluation achievement passing in objects to pass the experiment and control groups

\begin{tabular}{|c|c|c|c|c|c|c|c|c|}
\hline \multicolumn{2}{|c|}{ Subject } & \multicolumn{3}{|c|}{$\begin{array}{c}\text { Marks obtained in self-evaluation } \\
\text { achievement }\end{array}$} & \multicolumn{3}{|c|}{$\begin{array}{c}\text { Average of marks obtained in self-evaluation } \\
\text { achievement ratings }\end{array}$} & \multirow[t]{2}{*}{ Growth rate } \\
\hline Group & Number & $\begin{array}{c}\text { Before } \\
\text { experiment } \\
\text { (i) }\end{array}$ & $\begin{array}{l}\text { After } \\
\text { experiment } \\
\text { (ii) }\end{array}$ & $\begin{array}{l}\text { Difference } \\
\text { (i) and (ii) }\end{array}$ & $\begin{array}{c}\text { Before } \\
\text { experiment } \\
\text { (i) }\end{array}$ & $\begin{array}{l}\text { After } \\
\text { experiment } \\
\text { (ii) }\end{array}$ & $\begin{array}{l}\text { Difference } \\
\text { (i) and (ii) }\end{array}$ & \\
\hline \multicolumn{9}{|c|}{$\begin{array}{l}\text { Experiment } \\
\text { groups }\end{array}$} \\
\hline \multirow[t]{2}{*}{ Type A } & 1 & 50 & 93 & 43 & 48.0 & 80.0 & 32.0 & 1.7 \\
\hline & 2 & 46 & 67 & 21 & & & & \\
\hline \multirow[t]{3}{*}{ Type B } & 3 & 54 & 87 & 33 & 41.3 & 73.0 & 31.7 & 1.8 \\
\hline & 4 & 25 & 41 & 16 & & & & \\
\hline & 5 & 45 & 91 & 46 & & & & \\
\hline \multicolumn{9}{|l|}{$\begin{array}{l}\text { Control } \\
\text { group }\end{array}$} \\
\hline \multirow[t]{5}{*}{ Type C } & 6 & 41 & 74 & 33 & 46.4 & 71.0 & 24.6 & 1.5 \\
\hline & 7 & 45 & 86 & 41 & & & & \\
\hline & 8 & 51 & 51 & 0 & & & & \\
\hline & 9 & 49 & 74 & 25 & & & & \\
\hline & 10 & 46 & 70 & 24 & & & & \\
\hline
\end{tabular}

Table 2. Test results when a rating of more than "satisfactory in some way" was attained

\begin{tabular}{|c|c|c|c|c|}
\hline \multirow{2}{*}{$\begin{array}{l}\text { Method of } \\
\text { Instruction }\end{array}$} & \multicolumn{4}{|c|}{ Passing rate } \\
\hline & before & & after & \\
\hline Type A & 48.0 & $34.3 * *$ & 800 & \multirow{3}{*}{$5.0 *$} \\
\hline Type B & 41.3 & $45.2 * *$ & -73.0 & \\
\hline Type C & 46.5 & $46.9^{*}$ & 71.0 & \\
\hline
\end{tabular}

$* * \mathrm{P}<0.01, * \mathrm{P}<0.05$
Table 3. Test results when a rating of more than "almost satisfactory" was attained

\begin{tabular}{|c|c|c|c|c|}
\hline \multirow{2}{*}{$\begin{array}{l}\text { Method of } \\
\text { Instruction }\end{array}$} & \multicolumn{4}{|c|}{ Passing rate } \\
\hline & before & & ter & \\
\hline \multirow{2}{*}{ Type A } & \multirow{2}{*}{6.6} & $55.0^{* *}$ & 43.4 & \multirow{4}{*}{$25.1 * *$} \\
\hline & & & $9.0^{*}$ & \\
\hline Type B & 5.3 & $43.9 * *$ & $3.4^{+}$ & \\
\hline Type C & 6.8 & $34.8 * *$ & .8 & \\
\hline
\end{tabular}


training. However, future study will be necessary to determine whether acceleration of learning in FWP would indirectly raise the marks in the clinical training. It is believed that type A and B instruction would not lead the students to fail in the FWP because of poor marks.

In determination of the effect of SEAR on the PTPP, a siginificant difference between types A and $\mathrm{B}$ was observed. When the achievement level was set to be "almost attained", it can be said that the type A method was more effective in the PTPP than the conventional methods. When the achievement level was raised to "managed to be achieved", type A was more effective than type B. It can be presumed that type A would provide not only a proper instruction for difficult points to bring, but also penetration into the contents of learning.

However, in type $\mathrm{C}$, instruction was provided to students without pointing out the difficulty in learning. The training would proceed without correcting the students' mistakes.

Though type B reached the target for the individual students set by the SVs, it was considered less effective than type A, because understanding the performance level and the change in the instruction target were the same as the conventional methods. It was also considered quite doubtful whether the instruction target prepared by the teaching staff was properly conveyed to the SVs, and it was unknown that the instruction plan prepared by the SVs was implemented.

The adequacy and reliability of the SEA-Checklist in evaluating the performance level of the FWP was confirmed by the first study, and the performance level in each sucessive training became easier to understand by putting the SEA-Checklist to use.

The SEA-Checklist made it easier to prepare an instruction plan, and the instruction provided by both the teaching staff and SVs became effective for students with learning problems.

In conclusion, type A can be highly effective in learning PTPP, and made it easier to understand the performance level of the individual students, and instruction was provided to correct the targets individually.

The meaning of this very commonsense conclusion is important to examine the practical issues of problems in clinical training. It is considered that the type A instruction method in which teaching staff is positively involved will be required in the future, especially in instructing the students with learning problems. It was considered that failure can be prevented through adoption of the type A instructing method at an earlier stage of training.

As in the first study, the learning situations of individual students were classified into six categories. The performance level of two type A students each was variegated, though the details of each was not reported. Consideration should be given to solving problems individually in instructing the clinical FWP by thoroughly grasping the contents of the learning programs. Therefore the contents of individual instruction should be presented in the form of a case study in which reports were made on the students individually in the field of clinical training. Furthermore, it is important that FWP be executed with the targets of training and the habit of posttraining self-evaluation during the students' time in school. It is therefore necessary to work out a plan to make a self-diagnosis function on the SEA-Checklist. This time an evaluation of others was made by the rating in clinical training, but it is necessary to introduce a checklist to evaluate others concerning of the difficulty of grasping the situation in detail. An evaluation of others by an expert can identify whether self-evaluation was accurate. The self-evaluation capabilities of the students will be raised by feedbacks of the results.

The evaluation of others made by the SVs and teaching staff makes it possible not only to grasp the achievement rating of the students, but also to determine the individual targets they made during evaluation of others and the effects of instruction executed. It became possible to reconsider a comprehensive instruction plan.

\section{CONCLUSION}

In the first study, the SEA-Checklist was used to determine which students made mistakes in the FWP and to evaluate their mistakes. It became easier to work out a plan for overall and for individual targets.

In instruction for the FWP, it was effective not only to post an overall target, but also to adopt a method of instruction to correct each situation by evaluating students as they participated in FWP. Using an instruction method of setting individual targets and executing them, as in type A instruction, turned out to be rather effective.

Though the current situation does not allow to 
use this method, it was suggested that the execution of an instruction method of at least the individual target proposed type (type B) was required. This method was considered effective for students who made no mistakes during the FWP.

Applying case studies using the SEA-Checklist of the SEAR is an important part of FWP programs and instruction methods for practical FWP are easily established.

It was suggested by this study that evaluations based on standardized items can improve a student's ability for accurate self-evaluation and is a necessary part of the SV's determination of the effects of instruction.

\section{REFERENCES}

1) Shimizu K: Clinical education in physical therapy; future prospect in the study for improvement of clinical education in physical therapy. Rigaku ryōhō jānaru 28 (7): 443-449, 1994 (in Japanese).

2) Shimizu K: A study on how to instruct students in field work performance; instructing students in learning the physical therapy practical process. Published Master Thesis Abstracts Collection, Department of Rehabilitation, Graduate School, Tukuba University: 79-80, 1995 (in Japanese). 